\title{
Documento
}

\section{Cadastramento domiciliar para programas de transferência de renda no município de São Paulo, focalizado no território e com uso de tecnologia de informação móvel}

\author{
Tatiana Gabriela Brassea Galleguillos* \\ Aline Firmino Brito** \\ Aparecida Rodrigues Hidalgo** \\ Maria Luiza Piccinini** \\ Rubens Augusto Dias Serralheiro** \\ Marcos Vicente Arouca***
}

\section{Introdução}

A Constituição Federal de 1988 representa uma conquista no que se refere à instituição da seguridade social no Brasil. Composta de políticas públicas voltadas para a saúde, a previdência social e a assistência social, considera-se determinante do debate sobre a inclusão dos programas de transferência de renda (PTRs) na agenda pública (Silva, 2007).

O processo de implantação de PTRs no Brasil iniciou-se em 1995, no âmbito municipal em Campinas, em Ribeirão Preto e em Santos, e posteriormente no município de São Paulo, por meio da institucionalização do Programa de Garantia de Renda Familiar Mínima Municipal (PGRFMM) em 2001 (Silva, 2007).

\footnotetext{
* Doutora em Educação. Coordenadora de projetos na Coordenadoria de Gestão de Benefícios, Secretaria de Assistência e Desenvolvimento Social, Prefeitura Municipal de São Paulo. Endereço: Praça Antonio Prado, 33, 14 andar - Centro — CEP 01010-010, São Paulo, Brasil. E-mail: tgalleguillos@prefeitura.sp.gov.br.

** Coordenadoria de Gestão de Benefícios, Secretaria de Assistência e Desenvolvimento Social, Prefeitura Municipal de São Paulo.

*** Coordenador da Coordenadoria de Gestão de Benefícios, Secretaria de Assistência e Desenvolvimento Social, Prefeitura Municipal de São Paulo.
} 
Em 2004, a criação do Ministério do Desenvolvimento Social e Combate à Fome (MDS) determinou o aumento significativo dos investimentos em políticas de proteção, assistência e desenvolvimento social, que se traduzem em PTRs, segurança alimentar e nutricional, assistência social e inclusão produtiva (Vaitsman, Rodrigues e Paes-Sousa, 2006).

Os PTRs orientam-se pela perspectiva de contribuir para a inclusão social das famílias pobres e extremamente pobres. Considera-se, aqui, como política estruturante, que inclusive demanda a expansão e a democratização de serviços sociais (Silva, 2007).

O Brasil conta com PTRs nas diferentes esferas de governo, inclusive específicos para o estado e o município de São Paulo. Encontram-se, em operação, no município de São Paulo os programas citados no quadro.

\section{Programas de transferência de renda em operação no município de São Paulo (2009)}

\begin{tabular}{|llc|}
\hline Programa & $\begin{array}{c}\text { Esfera governamental } \\
\text { responsável }\end{array}$ & $\begin{array}{c}\text { Ano de início } \\
\text { das atividades }\end{array}$ \\
\hline Renda Mínima Municipal & Municipal & 2001 \\
Ação Jovem & Estadual & 2005 \\
Renda Cidadã & Estadual & 2002 \\
Erradicação do Trabalho Infantil (Peti) & Federal & 2001 \\
Benefício de Prestação Continuada & Federal & 1996 \\
Agente Jovem & Federal & 2002 \\
Bolsa Família & Federal & 2004 \\
\hline
\end{tabular}

Fonte: Coordenadoria de Gestão de Benefícios/Smads (2009).

Desde 2002, a partir da Lei no 13.399, o município de São Paulo passou a ser constituído por 31 subprefeituras, seguindo os pressupostos de descentralização. Quanto à Secretaria Municipal de Assistência e Desenvolvimento Social da Prefeitura de São Paulo (Smads) está organizada com base no Decreto $n^{\circ}$ 48.359/2007 que, em acordo com as diretrizes de gestão municipal e com o conjunto de princípios constitucionais, rege a administração pública, especialmente a sua relação com o cidadão.

\footnotetext{
${ }^{1}$ O Decreto no 48.359/2007 "Dispõe sobre a organização da Smads, altera a denominação e a lotação dos cargos de provimento em comissão que especifica".
} 
No campo da assistência social, determina:

I - o estabelecimento da assistência social no município de São Paulo como política pública de direito do cidadão e dever do Estado no sistema de proteção social; II - a garantia no sistema de proteção social das seguranças sociais de sobrevivência, rendimento, autonomia, acolhida, convívio ou convivência familiar; III — a coordenação da formulação e a implementação da Política Municipal de Assistência Social e do Sistema Único de Assistência Social — SUAS na cidade de São Paulo.

(São Paulo, 2007)

Os PTRs estavam dispersos em várias secretarias, em 2005 passaram para a gestão da Smads e operacionalização da Coordenadoria de Gestão de Benefícios (CGB), conforme dispõe o art. 25 do citado decreto, em especial nas alíneas I a IV:

I - coordenar, implementar, acompanhar e controlar os programas de transferência de renda e benefícios continuados, articulando-os aos demais programas e serviços da assistência social, objetivando a elevação do padrão de vida dos usuários; II - formular diretrizes e promover ações intersetoriais com vistas à potencialização e à qualificação dos benefícios para atendimento das necessidades básicas; III — propor estudos, pesquisas e sistematização de informações e dados acerca da implementação dos benefícios de prestação continuada e de transferência de renda; IV - manter organizado sistema de informações e dados sobre os benefícios, com vistas ao planejamento, desenvolvimento e avaliação das ações.

(São Paulo, 2007)

Essa nova competência da Smads gerou um amplo debate sobre o significado dos ganhos reais para a população da cidade, as melhorias efetivas que esses programas proporcionariam e o salto qualitativo na direção de um combate efetivo à pobreza. Os determinantes desse debate foram a ocorrência de significativas alterações dos elementos estruturais dos programas quanto à concepção de pobreza e ao formato de alguns, agora associados às ações socioeducativas, assim como à necessidade de realizar cadastros das famílias mais vulneráveis, com maior eficácia, eficiência e efetividade.

A experiência anterior de cadastro, em postos fixos instalados temporariamente nas subprefeituras, evidenciou as dificuldades de focalização no território e atendimento às condicionalidades dos diferentes programas de 
transferência de renda. A realização de cadastro centralizado levou grande quantidade de pessoas aos postos, que não apresentavam infraestrutura suficiente para atender ao volume diário de público, além de facilitar o cadastro de pessoas não residentes no município de São Paulo, uma vez que no ato não era possível constatar o local de moradia e a veracidade do comprovante de residência.

Como consequência, a distribuição das cotas de benefícios estabelecidas pelos gestores federal, estadual e municipal não eram exclusivamente para a população residente no município, originando denúncias confirmadas em muitos casos.

Ressalta-se ainda que o município de São Paulo contava com uma demanda da ordem de 140 mil habitantes não cadastrados das áreas com alto e muito alto índice paulista de vulnerabilidade social (IPVS 5 e 6), além de número significativo de habitantes de cortiços, favelas e conjuntos habitacionais populares fora dessas áreas, mas que se enquadram nos critérios sociais e econômicos que determinam alta e muito alta vulnerabilidade, e não possuía equipe e estrutura própria para realizar cadastramento dessa envergadura.

A falta de integração dos cadastros, federal - Cadúnico; estadual ProSocial; e municipal - Banco de Dados do Cidadão (BDC), determinava divergências relacionadas às obrigatoriedades cadastrais e parâmetros de campos obrigatórios, levando à inserção de dados incorretos e/ou incompletos, configurando aos cadastros baixa qualidade e confiabilidade das informações, interferindo na identificação e avaliação das famílias.

Para tanto, considerou-se de extrema importância compatibilizar os bancos de dados, para os diferentes programas das várias instâncias. Evidenciou-se a necessidade de adequar o cadastro para atender aos diferentes bancos de dados.

As questões descritas levaram a CGB/Smads a adotar uma nova estratégia: cadastramento domiciliar focalizado no território, com uso de tecnologia de informação móvel. Este artigo apresenta e descreve essa iniciativa.

\section{Os programas de transferência de renda}

O Bolsa Família é considerado "um dos mais ambiciosos programas de benefício social na América Latina" (Zouain e Barone, 2008). Contudo, estados e municípios mantêm alguns programas de transferência de renda específicos, como o Programa de Garantia de Renda Familiar Mínima Municipal do Município de São Paulo, o Programa Renda Cidadã do Estado de São Paulo, além 
de programas específicos no âmbito federal, como o Programa de Erradicação do Trabalho Infantil (Peti), o Programa Agente Jovem (encerrado em 2008) e o Benefício de Prestação Continuada (BPC).

O Programa Bolsa Família (PBF) integra o Projeto Fome Zero e destinase a ações de transferência de renda com condicionalidades. Criado por meio da Lei no $10.836,{ }^{2}$

com a finalidade de unificar os procedimentos de gestão e execução das ações de transferência de renda do governo federal, especialmente as do Programa Nacional de Renda Mínima vinculado à educação, do Programa Nacional de Acesso à Alimentação (Pnaa), do Programa Nacional de Renda Mínima vinculado à Saúde - Bolsa Alimentação, do Programa Auxílio Gás e do Cadastramento Único do governo federal.

(Brasil, 2004)

Foi regulamentado pelo Decreto no $5.209,{ }^{3}$ que no art. $4^{\circ}$ estabelece os seguintes objetivos para o PBF: I — promover acesso à rede de serviços públicos, em especial de saúde, educação e assistência social; II — combater a fome e promover a segurança alimentar e nutricional; III — estimular a emancipação sustentada das famílias que vivem em situação de pobreza e extrema pobreza; IV - combater a pobreza; e V - promover a intersetorialidade, a complementaridade e a sinergia das ações sociais do poder público (Brasil, 2004).

$\mathrm{O}$ PBF pauta-se na articulação de três dimensões essenciais à superação da fome e da pobreza: a promoção do alívio imediato da pobreza, por meio de transferência direta de renda à família; o reforço do exercício de direitos sociais básicos nas áreas da saúde e da educação, o que contribui para que as famílias consigam romper o ciclo de pobreza entre gerações; e a coordenação de programas complementares, ${ }^{4}$ que tem como objetivo o desenvolvimento das famílias, de modo que os beneficiários do PBF consigam superar a situação de vulnerabilidade e pobreza (Brasil, 2008).

Estabelece a necessidade do controle social, com a participação da sociedade civil nos processos de planejamento, acompanhamento, monitoramento e avaliação das ações da gestão pública e na execução das políticas e progra-

\footnotetext{
${ }^{2}$ A Lei no 10.836 , de 9 de janeiro de 2004, cria o Programa Bolsa Família e dá outras providências.

${ }^{3}$ Decreto no 5.209 , de 17 de setembro de 2004, regulamenta a Lei no 10.836 .

${ }^{4}$ Programas complementares: programas de geração de trabalho e renda, alfabetização de adultos, fornecimento de registro civil e demais documentos.
} 
mas públicos. A ação conjunta entre estado e sociedade para compartilhar responsabilidades tem em vista aumentar o nível de eficácia e efetividade das políticas e programas públicos.

O PBF estabelece, ainda, um conceito de família ampliado, "família, a unidade nuclear, eventualmente ampliada por outros indivíduos que com ela possuam laços de parentesco ou de afinidade, que forme um grupo doméstico, vivendo sob o mesmo teto e que se mantém pela contribuição de seus membros" (Brasil, 2004).

Especificamente no município de São Paulo, o Programa de Garantia de Renda Familiar Mínima Municipal (PGRFMM), estabelecido pela Lei oㅡ $14.255,{ }^{5}$ tem como objetivos: I - assegurar a melhoria das condições de vida do grupo familiar, por meio da concessão de benefício pecuniário; II — promover o acesso do grupo familiar à rede socioassistencial do território do município; III - estimular a frequência escolar; e IV - fortalecer os vínculos familiares e a convivência comunitária (São Paulo, 2006).

O programa desenvolve ações, programas e atividades conjuntas destinadas ao atendimento integral da família, criança e adolescente, em articulação com outras secretarias do município de São Paulo (São Paulo, 2008).

Com relação aos critérios vigentes, são elegíveis as famílias que atendam os seguintes requisitos: residentes domiciliados no município de São Paulo há dois anos; renda per capita mensal inferior ou igual a $\mathrm{R} \$ 175$; com filhos e/ou dependentes com idade entre seis e 15 anos, matriculados em escola, com frequência igual ou superior a $85 \%$ e com carteira de vacinação atualizada dos filhos e/ou dependentes menores de sete anos (São Paulo, 2006).

Segundo o art. 10, "a complementação de renda das famílias constitui apoio financeiro temporário e será concedido pelo prazo de até 24 (vinte e quatro) meses, prorrogáveis mediante avaliação de resultados, a cargo da coordenação do programa" (São Paulo, 2006).

O Programa Renda Cidadã foi estabelecido pela Secretaria Estadual de Assistência Social (Seads), por meio da Resolução Seads no $1,{ }^{6}$ que em seu art. 1을 determina que:

o Programa Renda Cidadã tem como objetivo atender famílias em situação de pobreza, em especial oriundas dos bolsões de pobreza, mediante a transferên-

\footnotetext{
${ }^{5}$ Lei no 14.255 , de 28 de dezembro de 2006, dispõe sobre o Programa de Garantia de Renda Familiar Mínima Municipal no Município de São Paulo. Regulamentada pelo Decreto no 50.153, de 28 de outubro de 2008.

${ }^{6}$ Resolução Seads no 1 , de 2 de março de 2005.
} 
cia direta de renda, como apoio financeiro temporário do Estado e, também, ações com enfoque socioeducativo e de geração de renda, como contrapartida dos municípios parceiros.

(São Paulo, 2005)

Ressalta-se que este programa é operacionalizado pelo município de São Paulo, por meio da CGB/Smads. O município de São Paulo, por meio da Coordenadoria de Proteção Social Básica, se responsabiliza pelo enfoque socioeducativo e de geração de renda. Vale enfatizar que a inclusão de famílias no programa é mais restrita, provavelmente determinada pela renda per capita de R 100 muito baixa para o município de São Paulo.

Quanto aos programas voltados à população jovem ressalta-se que

na Constituição Federal de 1988, o art. 227 elegeu a criança e o adolescente como prioridade absoluta e o art. 7oㅡ, inciso XXXIII, modificado pela Emenda Constitucional no 20, de 16 de novembro de 1998, proíbe o trabalho noturno, perigoso ou insalubre a menores de 18 e de qualquer trabalho a menores de 16 anos, salvo na condição de aprendiz, a partir de 14 anos; na Lei no 8.069/90, Estatuto da Criança e do Adolescente (ECA), que em seu art. 60 ratifica a proibição do trabalho infantil e que em seu art. 62 considera que a condição de aprendiz diz respeito à formação técnico-profissional, ministrada segundo as diretrizes e bases da legislação em vigor.

(Brasil, 2001)

Assim, destaca-se o Peti, que tem como meta erradicar o trabalho infantil em atividades perigosas, insalubres, penosas e degradantes, tanto na zona urbana como na rural e tem como objetivos: possibilitar o acesso, a permanência e o bom desempenho de crianças e adolescentes na escola; implantar atividades complementares à escola — jornada ampliada; conceder uma complementação mensal de renda às famílias, através do Bolsa Criança Cidadã; proporcionar apoio e orientação às famílias beneficiadas; e promover programas e projetos de qualificação profissional e de geração de trabalho e renda junto às famílias.

Apresenta como condicionalidades para permanência das famílias no programa: a retirada de todos os filhos menores de 16 anos de atividades laborais; a manutenção de todos os filhos de sete a 15 anos na escola, com frequência escolar mensal de 85\%; o apoio à manutenção dos filhos nas atividades da jornada ampliada; a participação das famílias nas atividades educativas; a participação das famílias em programas e projetos de qualificação 
profissional e de geração de trabalho e de renda oferecidos, e inscrição correta no Cadastro Único da Caixa Econômica Federal.

Outro programa voltado para a população jovem é o Programa Ação Jovem, ${ }^{7}$ que tem como objetivo enfrentar a situação de vulnerabilidade que afeta os jovens de baixa renda, no estado de São Paulo, com idade entre 15 e 24 anos, com ensino fundamental incompleto e inseridos em famílias de baixa renda. Posteriormente, o benefício foi expandido para jovens com ensino médio incompleto, ${ }^{8}$ e houve aumento do limite da renda familiar.

Os idosos e as pessoas portadoras de deficiências também foram considerados prioridade para os programas de transferência de renda. O Benefício de Prestação Continuada (BPC) ${ }^{9}$ já estava previsto na Constituição Federal de 1988, além de constar no Estatuto do Idoso. O BPC é um direito constitucional, portanto, não existe uma dotação orçamentária para o programa, e de fato todos os que atendem ao critério de elegibilidade podem requerê-lo. Ressalta-se que o programa somente considera elegíveis as doenças incapacitantes para o trabalho e vida independente.

Como parte do programa, a proteção básica busca a integração desses beneficiários idosos em núcleos de convivência, especialmente em regiões de alta vulnerabilidade social. Espera-se, ainda, poder cumprir o que estabelece a Lei Orgânica da Assistência Social (Loas), §2으, "os programas voltados ao idoso e à integração da pessoa portadora de deficiência serão devidamente articulados com o benefício de prestação continuada..." (Brasil, 1993).

\section{3. Índice paulista de vulnerabilidade social no município de São Paulo}

Novos condicionamentos sociais e formas de controle social se apresentam diante do atual contexto, no qual a sociedade se afasta do estado do bem-estar social. A pobreza é considerada um fenômeno econômico derivado das relações capital x trabalho, determinadas pelos distintos interesses de classe.

\footnotetext{
${ }^{7}$ Programa Ação Jovem, instituído pelo Decreto no 48.699, de 1o de junho de 2004 .

8 O Programa Ação Jovem foi alterado pelo Decreto no 49.367, de 10 de fevereiro de 2005 e pelo Decreto $n^{\circ}$ 49.807, de 21 de julho de 2005. As normas operacionais básicas do programa estão definidas pela Resolução Seads no 8, de 8 de agosto de 2005 .

${ }^{9}$ O Benefício de Prestação Continuada foi regulamentado pela Lei Orgânica da Assistência Social no 8.742, de 7 de dezembro de 1993.
} 
A exclusão social caracteriza-se pelos processos determinados pelas relações sociais, a exemplo da desqualificação social, da precarização do trabalho e da desumanização do outro (Lopes, 2006). O modelo de desenvolvimento capitalista levou à produção de visões de mundo que convergem com a marginalização, a segregação e a espoliação (Lopes, 2006).

O conceito de pobreza é ampliado ao ser agregado ao de vulnerabilidade social, envolvendo todo o ciclo de vida familiar, a renda, a escolaridade e o contexto socioterritorial, ou seja, a inserção dos pobres na estrutura da sociedade está estreitamente relacionada à sua inserção nos segmentos laboral, educativo e residencial (Katzman, 2001).

A vulnerabilidade de um indivíduo, família ou grupos sociais refere-se à maior ou à menor capacidade de controlar as forças que afetam seu bem-estar, ou seja, a posse ou controle de ativos que constituem os recursos requeridos para o aproveitamento das oportunidades propiciadas pelo Estado, mercado ou sociedade (Katzman, 2001).

A vulnerabilidade à pobreza não se limita em considerar a privação de renda, central nas medições baseadas em linhas de pobreza, mas também a composição familiar, as condições de saúde e o acesso a serviços de saúde, o acesso e a qualidade do sistema educacional, a possibilidade de obter trabalho com qualidade e remuneração adequadas, a existência de garantias legais e políticas (Ferreira, Dini e Ferreira, 2006).

Neste artigo utilizou-se como referencial o trabalho desenvolvido pela Fundação Seade (2004) referente ao índice paulista de vulnerabilidade social (IPVS) e à respectiva classificação, segundo graus de vulnerabilidade:

v grupo 1 - nenhuma vulnerabilidade - engloba os setores censitários em melhor situação socioeconômica (muito alta), com os responsáveis pelo domicílio possuindo os mais elevados níveis de renda e escolaridade. Apesar de o estágio das famílias no ciclo de vida não ser um definidor do grupo, seus responsáveis tendem a ser mais velhos, com menor presença de crianças pequenas e de moradores nos domicílios, quando comparados com o conjunto do estado de São Paulo;

- grupo 2 - vulnerabilidade muito baixa - abrange os setores censitários que se classificam em segundo lugar, no estado, em termos da dimensão socioeconômica (média ou alta). Nessas áreas concentram-se, em média, as famílias mais velhas;

- grupo 3 - vulnerabilidade baixa - formado pelos setores censitários que se classificam nos níveis altos ou médios da dimensão socioeconômica e seu perfil demográfico caracteriza-se pela predominância de famílias jovens e adultas; 
v grupo 4 - vulnerabilidade média - composto pelos setores que apresentam níveis médios na dimensão socioeconômica, estando em quarto lugar na escala em termos de renda e escolaridade do responsável pelo domicílio. Nesses setores concentram-se famílias jovens, isto é, com forte presença de chefes jovens (com menos de 30 anos) e de crianças pequenas;

v grupo 5 - vulnerabilidade alta - engloba os setores censitários que possuem as piores condições na dimensão socioeconômica (baixa), estando entre os dois grupos em que os chefes de domicílios apresentam, em média, os níveis mais baixos de renda e escolaridade. Concentra famílias mais velhas, com menor presença de crianças pequenas;

v grupo 6 - vulnerabilidade muito alta - o segundo dos dois piores grupos em termos da dimensão socioeconômica (baixa), com grande concentração de famílias jovens. A combinação entre chefes jovens, com baixos níveis de renda e de escolaridade e presença significativa de crianças pequenas permite inferir ser esse o grupo de maior vulnerabilidade à pobreza.

No Brasil, de 2001 a 2004, a desigualdade de renda per capita caiu de forma contínua e substancial, alcançando seu menor nível nos últimos 30 anos. Essa desconcentração levou a uma expressiva redução da pobreza e da extrema pobreza (Ipea, 2006).

A renda média dos 10\% mais pobres cresceu a uma taxa anual média de $7 \%$, já a renda média nacional declinou $1 \%$ ao ano. Como a renda per capita total não cresceu no período, toda a queda da pobreza pode ser atribuída à redução na desigualdade. A queda de $4 \%$ da desigualdade de renda determinou redução de $3,2 \%$ das pessoas extremamente pobres, o que equivale a retirar mais de 5 milhões de brasileiros dessa condição (Ipea, 2006).

Os determinantes imediatos da renda familiar per capita considerados foram: características demográficas das famílias; transferência de renda; remuneração de ativos; acesso ao trabalho, desemprego e participação no mercado de trabalho e distribuição dos rendimentos do trabalho (Ipea, 2006).

Especificamente para as transferências de renda, a sua efetividade na redução da desigualdade de renda depende de valores dos benefícios pagos e da cobertura de atendimento da população carente. As transferências governamentais contribuíram com cerca de $1 / 3$ da redução na concentração de renda, considerados três tipos de transferências públicas: pensões e aposentadorias, benefício de prestação continuada e os benefícios do Bolsa Família e outros programas de transferência de renda (Ipea, 2006). 
Os critérios de elegibilidade dos PTRs seguem a lógica da Lei Orgânica da Assistência Social, Loas (1993), cujo acesso à assistência é direito daqueles que dela necessitam.

Entre os fatores que compõem as situações de vulnerabilidade social estão, de acordo com Busso (2001):

a fragilidade ou desproteção ante as mudanças originadas em seu entorno, o desamparo institucional dos cidadãos pelo Estado; a debilidade interna de indivíduos ou famílias para realizar as mudanças necessárias a fim de aproveitar o conjunto de oportunidades que se apresenta; a insegurança permanente que paralisa, incapacita e desmotiva no sentido de pensar estratégias e realizar ações com o objetivo de lograr melhores condições de vida.

No município de São Paulo, a população das áreas com maior prevalência de IPVS 5 e 6 era de 2.850.407 habitantes, à época do estudo realizado pela Fundação Seade (2004), perfazendo $27,4 \%$ da população total do município de São Paulo. Após quantificada, qualificada e territorializada, tornou-se o público-alvo prioritário para a política de assistência social do município, uma vez que $352.251(3,4 \%)$ habitantes foram considerados de IPVS 5 e $993.326(9,5 \%)$ habitantes como de IPVS 6, o que corresponde a $47,06 \%$ da população das subprefeituras com maior prevalência de IPVS 5 e 6 , conforme tabela 1 .

Tabela 1

População por subprefeituras e distritos administrativos nas áreas com maior prevalência de IPVS 5 e 6, São Paulo

\begin{tabular}{|lccc|}
\hline Subprefeitura & Distrito administrativo & População 2000 & $\%$ \\
\hline Freguesia/Brasilândia & Anhanguera & 38.427 & 0,4 \\
& Brasilândia & 247.328 & 2,4 \\
Perus & Perus & 70.689 & 0,7 \\
Jaçanã/Tremembé & Tremembé & 163.803 & 1,6 \\
São Mateus & Jardim Helena & 139.106 & 1,3 \\
& Vila Andrade & 73.649 & 0,7 \\
& São Rafael & 125.088 & 1,2 \\
& Iguatemi & 101.780 & 1 \\
& Vila Jacuí & 141.959 & 1,4 \\
São Miguel & São Miguel & 97.373 & 0,9 \\
\hline
\end{tabular}




\begin{tabular}{|llcc|}
\hline Subprefeitura & Distrito administrativo & População 2000 & $\%$ \\
\hline Ermelino Matarazzo & Ermelino Matarazzo & 106.838 & 1 \\
Penha & Cangaíba & 137.442 & 1,3 \\
Vila Maria & Vila Maria & 113.845 & 1,1 \\
Cidade Tiradentes & Cidade Tiradentes & 190.657 & 1,8 \\
Itaquera & Parque do Carmo & 64.067 & 0,6 \\
& José Bonifácio & 107.082 & 1 \\
Campo Limpo & Capão Redondo & 240.793 & 2,3 \\
M'Boi Mirim & Jardim Ângela & 245.805 & 2,4 \\
Parelheiros & Parelheiros & 102.836 & 1 \\
& Marsilac & 8.404 & 0,1 \\
Capela do Socorro & Grajaú & 333.436 & 3,2 \\
Subtotal IPVS 5 e 6 & & 2.850 .407 & 27,4 \\
Outras subprefeituras & & 7.567 .039 & 72,6 \\
Total & & 10.417 .446 & 100 \\
\hline
\end{tabular}

Fonte: Fundação Seade (2004), citada em IBGE censo demográfico (2000).

A distribuição espacial dessa população, por distrito administrativo, considerando os IPVS 5 e 6, de "vulnerabilidade alta" e "muito alta", apresentava uma concentração maior nas áreas mais distantes do centro expandido, embora este também registrasse agrupamentos sociais com as mesmas características.

\section{O uso da tecnologia de informação}

A tecnologia de informação (TI) passou a ser importante componente para o sucesso das empresas no aproveitamento dos benefícios, tanto em nível estratégico quanto operacional. A utilização de TI oferece benefícios relacionados a custo, qualidade, flexibilidade, produtividade e inovação. "O desafio das organizações é determinar o mais precisamente possível quais os dados realmente ofertados e desejados, pois tal identificação será a base para a confirmação desses benefícios" (Albertin e Albertin, 2008:278).

Ainda se pode denominar os benefícios do uso de TI em tangíveis, que influenciam diretamente os resultados e os intangíveis que influenciam no desempenho mas não diretamente nos resultados (Albertin e Albertin, 2008).

A globalização e o grande volume de informações manipuladas, geradas e armazenadas por inúmeras empresas, têm nos avanços da tecnologia de 
informação a possibilidade do uso de redes e a integração das informações, que determinam efetivo suporte para a tomada de decisão em diversos níveis. Entretanto, ainda há deficiência na obtenção ágil de informações estratégicas, o que determinou o cadastramento domiciliar com uso de TI, que será descrito logo a seguir.

Ressalta-se, ainda, que a política de tecnologia e informação preconizada pelo Ministério de Desenvolvimento Social e Combate à Fome (MDS) considera necessário "consolidar, a partir de conjunto de diretrizes estabelecidas, um modelo de atuação que abra caminhos para alcançar soluções tecnológicas numa perspectiva de melhoria contínua em direção aos objetivos desejados" e tem como um dos objetivos "garantir melhores processos e meios necessários à produção de informações operacionais, gerenciais e estratégicas" (MDS, 2007:28-29).

\section{Cadastro domiciliar focalizado no território com uso de tecnologia de informação móvel}

O cadastro domiciliar focalizado no território foi empreendido pela CGB/ Smads, em parceria com as subprefeituras, Secretaria Municipal da Habitação (Sehab), Secretaria Municipal da Saúde (SMS) e Secretaria Municipal da Educação (SME) do município de São Paulo e, com a participação da empresa "Ibope Inteligência", contratada em 2008 para a execução do cadastramento domiciliar na cidade de São Paulo.

O objetivo foi o de cadastrar 80 mil famílias para inclusão nos bancos de dados utilizados por Smads, ampliando o acesso da população aos benefícios dos programas de transferência de renda.

Optou-se pelo cadastramento domiciliar e eletrônico, com uso de tecnologia de informação móvel - smartphone, focalizado no território, tendo em vista a capacidade de desempenho dessa estratégia diante da demanda. O cadastro domiciliar com uso de tecnologia de informação permite localizar com maior rapidez a população, com maior segurança e fidelidade dos dados, maior extensão territorial de domicílios cadastrados, portanto, de número de famílias visitadas e maior agilidade na inserção de dados nos respectivos bancos, consequentemente, maior rapidez na inserção nos programas sociais e de transferência de renda.

A tecnologia de informação também foi utilizada para tratamento das multiplicidades entre os bancos de dados do CadÚnico e BDC, eliminou as inconsistências, que antes atrasavam o processo. Os procedimentos de con- 
sulta foram padronizados e foi elaborado um plano baseado em estrutura de backup do CadÚnico e atualizações simultâneas, que resultou em 70\% de atualização/revisão dos bancos de dados.

Quanto às especificações funcionais e procedimentos técnicos utilizouse o SQL Server 2000 para extrair dados em tabelas do CadÚnico. Foram criadas tabelas de apoio para importação dos registros do arquivo texto, tabelas de acordo com o tipo de registro e campos específicos, assim como chaves com relacionamento básico entre os registros das mesmas, além de storeds procedures do banco de dados para a realização de carga e atualização do arquivo. Todo o processo usa ferramentas de mercado que podem ser absorvidas pelas equipes da prefeitura.

O processo de cadastramento foi iniciado em meados de 2007, foram escolhidos os setores censitários para cadastro, promovidas reuniões com os subprefeitos e suas equipes para apresentação da metodologia do cadastramento e solicitação de apoio local, assim como mobilização dos profissionais dos equipamentos sociais e organizações conveniadas, além das lideranças locais para viabilizar o cadastramento.

Até julho de 2008, a divulgação das informações ao público sobre o cadastramento foi de responsabilidade do Serviço de Atendimento ao Cidadão (SAC), Serviço "156", no serviço telefônico do "Ibope Inteligência" e nos próprios Cras das subprefeituras.

Foi realizada capacitação das equipes de trabalho da empresa "Ibope Inteligência" para desenvolver as atividades junto à população e foram utilizadas estratégias para envolver os servidores no processo. Os servidores participantes tiveram a oportunidade de se apropriar da metodologia do cadastramento domiciliar focalizado no território em áreas com IPVS 5 e 6 . Desse processo resultou uma nova visão da realidade social em que atuam e a incorporação de novos conhecimentos, habilidades e competências, gerando proatividade nos seus desempenhos. O resultado evidencia-se pela capacidade de articulação e de trabalho em rede estabelecida e consequente sucesso do empreendimento.

O número de cadastradores totalizou 200, capacitados em dois momentos: treinamento teórico $-8 \mathrm{~h}$ /aula; e treinamento prático - 40h/aula, referente a acompanhamento em campo durante uma semana. O conteúdo teórico, conduzido pela Smads, focalizou-se na sensibilização quanto à importância da responsabilidade do cadastrador no projeto e no fornecimento de informações sobre: a Smads e CGB, os programas sociais da Smads e PTRs, as regiões de realização do cadastramento e as famílias-alvo do projeto, o instrumental utilizado, as ações a serem efetuadas, além do horário de trabalho e fluxo de produção; capacitação para realização do arrolamento (anotação 
sobre visita realizada aos domicílios), desde a utilização e preenchimento da folha de arrolamento.

O treinamento em campo, em situação de cadastramento real, foi focado na selagem dos domicílios, na utilização prática do equipamento eletrônico móvel (smartphone) para o preenchimento do formulário Cadúnico e seus anexos, e para a operação do processo de registro fotográfico digital dos documentos das famílias cadastradas.

A capacitação dos cadastradores permitiu a compreensão de sua competência na produção de cadastros com qualidade para comporem o banco de dados. Para cumprir a meta houve adequação de horários para atender as necessidades das famílias. O seu envolvimento levou a uma compreensão mais ampla do papel social do cadastramento.

Para a inserção de informações nos bancos de dados desenvolveu-se um software específico, para uso no smartphone, considerando todos os campos obrigatórios e as consistências necessárias, impedindo a omissão de informações importantes, segundo a sequência de campos do formulário CadÚnico e do formulário do BDC. Também foram implementadas rotinas para a transferência de dados direta aos sistemas de informação do Ibope e posteriormente encaminhados para Smads.

A instituição contratada teve como incumbência a abordagem, a coleta, a verificação de consistência, a organização e a compatibilização dos dados, para a inclusão nos sistemas informatizados, e o enfrentamento das externalidades negativas locais. Ressalta-se que o pagamento da empresa contratada estava vinculado à entrega de cadastros válidos.

Realizou-se pré-teste do aplicativo com 200 famílias, que, após aprovação, foi homologado pala CGB/Smads para execução do cadastro. O processo teve sua continuidade com a elaboração de croquis dos setores censitários, a impressão de mapas de planejamento do trabalho, a elaboração do cronograma e de roteiros dos setores e composição das equipes de cadastro.

Em janeiro de 2008, iniciou-se o cadastramento com abordagem de todos os domicílios dos setores indicados. A documentação exigida pelos programas de transferência de renda foi fotografada e arquivada em meio digital. A família que não apresentou os documentos imediatamente para o cadastramento recebeu novas visitas, previamente agendadas.

O cadastramento teve como controle social a divulgação e a discussão com a participação de todos os atores sociais das regiões, em reuniões locais na fase inicial e durante todo o processo. A base de dados das famílias cadastradas pôde ser disponibilizada em meio digital, com supervisões de assis- 
tência social (SAS), a partir de 2009, denominadas Centro de Referência de Assistência Social (Cras), de cada uma das 31 subprefeituras.

As famílias cadastradas podem obter informações sobre as condicionalidades dos programas de transferência de renda, bem como a sua inclusão ou não nos mesmos, por meio dos Cras e serviço "156" ou outro canal de atendimento ao cidadão, caracterizando a transparência do processo.

O processo foi centralizado na CGB/Smads para organização e controle de suas diferentes fases, assim como da avaliação dos setores censitários que estavam em processo de cadastramento. Para o monitoramento, duas estratégias foram adotadas: reuniões semanais com a equipe de coordenação da instituição parceira para enfrentamento de quaisquer problemas e imediata superação, com apresentação de relatórios de produção e acompanhamento em campo que evitou o crescimento de problemas locais, favorecendo a produção de cadastros, racionalizando os recursos e garantindo a credibilidade da implantação do processo.

As equipes técnicas locais detinham pleno conhecimento de que a realização dos cadastros domiciliares era fundamental para efetivar o trabalho de assistência social no seu território. Levar isso a efeito era de suma importância para o trabalho posterior com famílias e sua inclusão em programas sociais com ou sem transferência de renda.

A metodologia participativa para desenvolver e facilitar o processo de cadastramento resultou no efetivo cadastro de famílias, assim como reverteu expectativas negativas anteriores referentes à dificuldade de inclusão das mesmas em programas sociais e determinou o empoderamento dos servidores.

O incentivo das equipes partiu da sensibilização prévia da necessidade do cadastro para inserção das famílias em programas sociais, com ou sem transferência de renda. Quanto à empresa contratada, o pagamento só foi efetuado mediante a entrega de base de dados com cadastros válidos.

Foram utilizados recursos federais destinados para pagamento do contrato com a empresa contratada, com o pagamento realizado por cadastro válido, que incluiu: a aquisição de materiais como selos de identificação, cartas e folhetos, coletes, mochilas, pastas, identificadores dos cadastradores, manuais de orientação em campo, canetas, papel, planilha de arrolamento, mapas, croquis impressos, cópias reprográficas e outros; o pagamento de impostos, taxas, serviços, salários, encargos, demais despesas correntes para a realização do cadastramento; a aquisição de equipamentos - 246 smartphones e 195 máquinas fotográficas digitais, e o desenvolvimento de software compatível com o conteúdo do cadastro utilizado. 
A organização e o desenvolvimento do trabalho em campo foram de responsabilidade da empresa contratada, que contou com um coordenador geral, três assistentes de coordenação, três coordenadores de campo, 18 supervisores de campo, 12 auxiliares de supervisão, três profissionais de suporte e verificação e 200 entrevistadores.

A CGB/Smads disponibilizou dois técnicos da equipe de cadastramento e monitoramento dos PTRs, três profissionais da equipe de tecnologia da informação, um contador e um assistente administrativo. Quanto aos recursos materiais, elaborou planilhas com os setores censitários selecionados para o cadastramento, contribuiu com veículos para transporte dos técnicos até os locais de cadastramento, assim como projetor multimídia, computador e laptop para as reuniões de preparação e divulgação do cadastramento.

A comunidade contribuiu por meio das organizações sociais e associações de moradores, cujas lideranças participaram ativamente nas atividades do cadastramento, acompanhando o trabalho de campo e com oferta de infraestrutura de seus próprios espaços como ponto de apoio para as equipes de cadastradores.

O trabalho caracterizou-se pela descentralização das atividades e pela intersetorialidade, com a participação de várias secretarias. A Secretaria Municipal da Saúde (SMS) teve a participação das equipes do Programa Saúde da Família (PSF), que facilitaram o acesso das equipes de cadastradores aos domicílios. A Secretaria Municipal de Educação (SME) participou ao fornecer os comprovantes de matrícula e frequência escolar das crianças e adolescentes das famílias cadastradas, atendendo a uma das condicionalidades para inclusão nos programas de transferência de renda.

A Secretaria Municipal de Habitação (Sehab) apontou e disponibilizou as famílias beneficiadas e cadastradas para as obras de reurbanização de favelas e moradias de baixa renda, já cadastradas no CadÚnico. Também participou o Projeto de Inclusão Social Urbana "Nós do Centro" - cadastramento das famílias das áreas de abrangência de escritórios de inclusão social (EIS).

Foi realizado o controle de qualidade, por equipes específicas de supervisão, a partir de amostra de $30 \%$ dos cadastros e respectivos documentos, escolhidos aleatoriamente. Reuniões de avaliação semanais ocorreram durante todo o processo para apresentação dos relatórios de monitoramento e de controle das metas. Em julho de 2008, o processo foi encerrado com a transferência dos dados para a base digital da Smads e entrega do respectivo software pela instituição contratada para ser utilizado em próximos cadastramentos. 
Um indicador relevante é a ausência de denúncias durante todo o processo conduzido pela Smads, seja através do serviço "156", ou por meio da Ouvidoria Geral do Município de São Paulo, bem como de quaisquer outras origens. As denúncias eventualmente encaminhadas à CGB/Smads referiamse a indivíduos, sem nenhum vínculo com a Smads, que tentavam fazer cadastramento cobrando taxas, não obtendo êxito, uma vez que o cadastro Smads era gratuito. Os cadastradores se apresentaram devidamente identificados e uniformizados, e realizaram visitas domiciliares iniciais com a entrega de carta de orientação e folhetos explicativos.

Como mecanismo de controle das metas, utilizou-se como indicador de desempenho "a proporção de cadastros realizados e validados". Os dados foram extraídos das planilhas entregues, com a produção semanal dos cadastros. Outro mecanismo de controle e avaliação de desempenho foi o acompanhamento semanal pelas equipes de coordenação da CGB/Smads e empresa "Ibope Inteligência".

Os indicadores de monitoramento da planilha semanal eram: identificação do programa social de referência, nome da subprefeitura, distrito administrativo e região de atuação, número de domicílios do Censo IBGE/ 2000, IPVS, código dos setores censitários, número de domicílios selados, situação de selagem (em andamento ou encerrada), data de início do cadastramento nos locais, quantidade de cadastros realizados, percentagem de aproveitamento e totalização por distritos administrativos e subprefeituras.

A base de dados foi periodicamente encaminhada à CGB/Smads para verificação de consistência e validação dos dados de cada cadastro, o que determinava a liberação de pagamento da produção à empresa contratada.

Esse monitoramento permitiu avaliar as equipes e reorientar o trabalho, conforme as necessidades da CGB/Smads, assim como a mobilização dos atores sociais dos locais com metas ainda não alcançadas.

No período de seis meses realizaram-se 70.215 cadastros, distribuídos conforme as categorias de frentes de cadastramento indicadas na tabela 2 , evidenciando o alcance da meta de 10 mil cadastros por mês.

Ressalta-se que do total, 53.589 cadastros representando 76,3\% estão vinculados diretamente aos serviços prestados pela Smads, mediante seus programas sociais, com ou sem transferência de renda. $\mathrm{O}$ montante de cadastros efetuados para os programas da Sehab $(23,7 \%)$ mostra o resultado positivo da parceria estabelecida, que poderá ser replicada no âmbito municipal, estadual e federal. 
Tabela 2

Produção total de cadastros - São Paulo, janeiro/julho 2008

\begin{tabular}{|lrr|}
\hline Frente de cadastramento & \multicolumn{1}{c|}{ Total } & \multicolumn{1}{c|}{$\%$} \\
\hline Programa Ação Família & 45.873 & 65,30 \\
Secretaria Municipal da Habitação & 16.626 & 23,70 \\
Projeto de Inclusão Social Urbana "Nós do Centro" & 3.654 & 5,20 \\
Áreas Coord. Gestão Benefícios & 2.101 & 3,00 \\
Albergues & 1.857 & 2,60 \\
Abrigo - crianças e adolescentes & 104 & 0,10 \\
Total de cadastros & 70.215 & 100,00 \\
\hline
\end{tabular}

Fonte: Ibope Inteligência/Smads/CGB (2008).

Enviou-se 69.590 cadastros para o banco CadÚnico do Programa Bolsa Família e para o BDC, correspondente a 99,10\% de aproveitamento dos cadastros feitos. Foram ainda incluídos 8 mil no Banco dos Programas de Transferência de Renda do Estado de São Paulo (ProSocial).

Os cadastros foram enviados aos bancos de dados dos programas de transferência de renda, por lotes, num total de 25. O índice de rejeição de cadastros foi progressivamente diminuindo, o que significa que a qualidade dos cadastros, portanto, a verificação das consistências foi aperfeiçoada no decorrer do desenvolvimento do trabalho, conforme demonstra a figura.

\section{Índice de rejeições de cadastros enviados para bancos de dados, de programas de transferência de renda, segundo lote no primeiro envio, município de São Paulo (2008)}

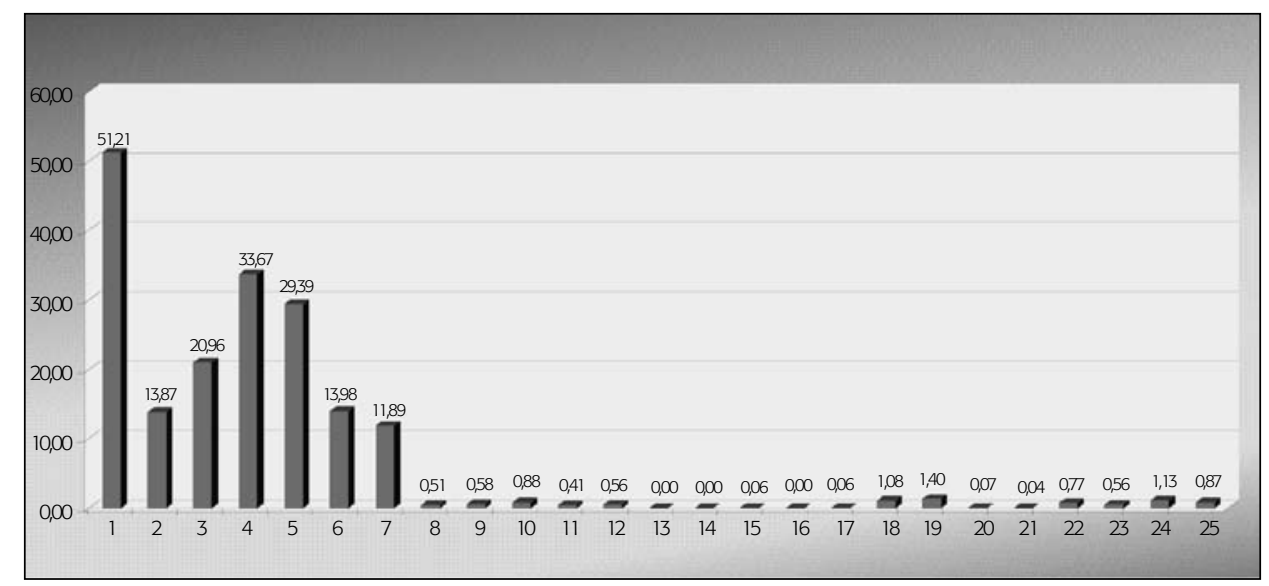


Evidencia-se que a utilização de tecnologia de informação permitiu a análise das consistências dos cadastros, o que influenciou na qualidade dos cadastros e na inclusão de famílias nos PTRs, pois a má qualidade de cadastros pode determinar a não inclusão de famílias que atendem a todos os requisitos.

\section{Considerações finais}

O trabalho coletivo e o intersetorial possibilitaram a valorização do servidor municipal, a partir de sua participação na construção coletiva e avaliação de todo o processo. As equipes estiveram sempre mobilizadas, mesmo fora de seus horários regulares de trabalho, para a continuidade de suas atividades e disponíveis para colaboração na superação de quaisquer eventualidades negativas, demonstrando a motivação do grupo.

O bom desempenho e a superação das dificuldades foram determinados pela organização do trabalho das equipes envolvidas no processo de cadastramento, tanto as da instituição contratada quanto as das SAS das subprefeituras. Ambas conheciam suas competências, suas áreas de atuação, a metodologia do cadastramento, os prazos, os fluxos e o papel de cada um dos segmentos no conjunto do trabalho. A existência de um núcleo de coordenação central na CGB/Smads foi fundamental para o competente exercício do trabalho em equipe e da manutenção da rede.

O desenvolvimento de um software pelo município de São Paulo representou um avanço no âmbito brasileiro, uma experiência de gestão pioneira no que se refere ao uso da tecnologia e de novos conhecimentos para a realização de cadastro de famílias. A consistência do processo, mesmo com todas as adversidades e complexidades é um grande passo para a integração de cadastros de programas sociais no âmbito da municipalidade paulistana e pode ainda ser viável em qualquer região do país.

A substituição do cadastramento manual pelo eletrônico buscou melhorar a relação custo/benefício. O preenchimento digital de cadastros reduziu o tempo para inclusão das famílias nos programas sociais, não houve gasto com arquivo de documentos e houve maior facilidade para consultas aos cadastros e respectiva documentação. Quanto aos munícipes, evitou-se gastos com cópias de documentos e locomoção, assim como tempo por deslocamento.

A digitalização representou maior segurança e fidelidade dos dados obtidos, consistentes ganhos em extensão territorial de domicílios cadastrados e redução de tempo para alimentar o banco de dados. 
O trabalho focalizado no território possibilitou atualizar os croquis dos setores censitários escolhidos e aos Cras reconhecerem as condições sociais das famílias, o que contribuiu para melhor assistência descentralizada. Evidenciou a necessidade de análise da realidade local para garantir a inclusão de todas as famílias de IPVS 5 e 6, por vezes para além dos limites do setores censitários escolhidos.

Apesar de todo o processo estar desenhado, se fez alguns ajustes, em face dos elementos-surpresa presentes, que exigiram do conjunto dos participantes, a prontidão, o envolvimento, a criatividade e a disposição para o "novo", caracterizando-se como um processo do "aprender-fazendo", recurso capaz de gerar integração, compromisso e apropriação dos conhecimentos gerados por todos os atores envolvidos.

Na perspectiva da inserção das famílias em programas sociais e de transferência de renda, ampliou-se consistentemente o banco de dados do município de São Paulo, atingindo o objetivo proposto.

\section{Referências}

ALBERTIN A. L., ALBERTIN, R. M. M. Benefícios do uso da tecnologia de informação para o desempenho empresarial. RAP, v. 42, n. 2, p. 275-302, 2008.

BRASIL. Lei no 8.069, de 13 de julho de 1990. Dispõe sobre o estatuto da criança e do adolescente e dá outras providências. Diário Oficial da União, 16 jul. 1990.

. Lei Orgânica da Assistência Social, Lei no 8.742, de 7 de dezembro de 1993. Dispõe sobre a organização da assistência social e dá outras providências. Diário Oficial da União, 8 dez. 1993.

. Portaria MPAS no 458, de 4 de outubro de 2001. Estabelece diretrizes e normas do Programa de Erradicação do Trabalho Infantil. Diário Oficial da União, 5 out. 2001.

. Decreto no 5.209, de 17 de setembro de 2004. Regulamenta a Lei no 10.836, de 9 de janeiro de 2004, que cria o Programa Bolsa Família e dá outras providências.

. Lei no 10.836, de 9 de janeiro de 2004. Cria o Programa Bolsa Família e dá outras providências.

. Portaria no 555, de 11 de novembro de 2005. Estabelece normas e procedimentos para a gestão de benefícios do PBF. Diário Oficial da União, 222. ed., 21 nov. 2005. 
. Instituto de Pesquisa Econômica Aplicada. Nota técnica: a recente queda da desigualdade de renda no Brasil, 2006.

. Secretaria de Assuntos Estratégicos. Instituto de Pesquisa Econômica Aplicada. Nota técnica sobre a recente queda da desigualdade de renda no Brasil. Brasília, 2006.

. Ministério do Desenvolvimento Social e Combate à Fome. Programa Bolsa Família. Brasília. 2008. Disponível em: <www.mds.gov.br/bolsafamilia/programa_bolsa_familia $>$. Acesso em: 28 out. 2008.

BUSSO, G. Vulnerabilidade social: nociones e implicâncias de políticas para Latinoamerica a inícios del siglo XXI. In: SEMINÁRIO INTERNACIONAL LAS DIFERENTES EXPRESIONES DE LA VULNERABILIDAD EM AMÉRICA LATINA Y EL CARIBE. Anales... Santiago, Chile, 2001.

FERREIRA M. P.; DINI, N. P.; FERREIRA, S. P. Espaços e dimensões da pobreza nos municípios do estado de São Paulo - índice paulista de vulnerabilidade social — IPVS. São Paulo em Perspectiva, v. 20, n. 1, p. 5-17, 2006.

KATZMAN, R. Seducidos y abandonados: el aislamento social de los pobres urbanos. Revista de la Cepal, v. 75, p. 172-189, 2001.

LOPES, J. R. Exclusão social, privações e vulnerabilidade: uma análise dos novos condicionamentos sociais. São Paulo em Perspectiva, v. 20, n. 1, p. 5-17, 2006.

RODRIGUES, R. W. S.; LOPES, M. H. C. Política de Tecnologia e Informação do Ministério do Desenvolvimento Social e Combate à Fome. In: RODRIGUES, R. W. S.; TAPAJÓS, L. (Orgs.). Rede Suas: gestão e sistema de informação para o Sistema Único de Assistência Social. Brasília: Secretaria Nacional de Assistência Social, 2007.

SÃO PAULO. Fundação Sistema Estadual de Análise de Dados. Índice paulista de vulnerabilidade social. 2004. Disponível em: <www.seade.gov.br/produtos/ipvs>. Acesso em: 20 abr. 2009.

. Resolução Seads 1, de 1ำ de março de 2005. Dispõe sobre o programa Renda Cidadã, estabelece normas operacionais básicas para o programa e dá outras providências correlatas.

. Lei no 14.255 , de 28 de dezembro de 2006. Dispõe sobre o Programa de Garantia de Renda Familiar Mínima Municipal no Município de São Paulo.

. Decreto no 50.153, de 28 de outubro de 2008. Regulamenta a Lei no 14.255 , de 28 de dezembro de 2006. 
SILVA, M. O. S. O Bolsa Família: problematizando questões centrais na política de transferência de renda no Brasil. Revista Ciência \& Saúde Coletiva, v. 12, n. 6, p. 1429-1439, 2007.

VAITSMAN, J.; RODRIGUES, R. W. S.; PAES-SOUSA, R. O sistema de avaliação e monitoramento das políticas e programas sociais: a experiência do Ministério do Desenvolvimento Social e combate à fome do Brasil. Unesco, 2006.

ZOUAIN, D. M.; BARONE, F. M. Qualidade da gestão das condicionalidades do Programa Bolsa Família: uma discussão sobre o índice de gestão descentralizada. Revista de Administração Pública, v. 42, n. 3, p. 625-641, 2008. 